troponin $\mathrm{T}$, were identified through records of ED visits and cross-referenced to other registers. The outcome measure was ACS, defined as a discharge diagnosis of $\mathrm{MI}$, unstable angina requiring urgent revascularisation, or death within 30 days (for directly discharged only). The association between RA and the outcome was assessed using logistic regression.

Results: ACS was more common in patients with RA (4.7\%) than in subjects without RA (3.3\%) - but this difference was largely attributable to RA patients being older and, upon taking age and gender into account, not statistically significant $(p=0.13)$. Overall and across all individuals with chest pain and/or a troponin T test taken, RA was not associated with ACS when adjusting for age, demographics and comorbidity, odds ratio $(\mathrm{OR}) 1.24,95 \%$ confidence interval $(\mathrm{Cl}): 0.95-1.61$. In analyses restricted to patients presenting with chest pain (irrespective of troponin T test status, $n=49$ 283), a significant association between RA and ACS was observed (adjusted OR 1.40 95\% Cl 1.01-1.96).

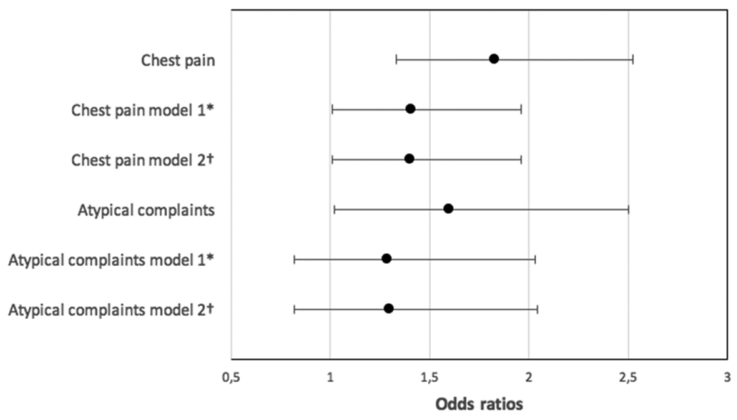

Figure 1 Odds ratios for myocardial infarction (MI) in rheumatoid arthritis (RA) patients compared with unexposed. Patients with suspected MI in the emergency department (ED) grouped by presence of chest pain. Other chief complaints than chest pain labelled as atypical complaints. MI refers to combined outcome of MI or 30 day major cardiac event (MACE). * Model 1: adjusted for age, gender, hospital, year of ED visit. $\dagger$ Model 2: adjusted for age, gender, hospital, year of ED visit, smoking, estimated glomerular filtration rate (eGFR), hypertension, hyperlipidaemia, diabetes mellitus, obesity, atrial fibrillation, heart failure and previous cardiovascular disease. Previous cardiovascular disease meant having one of the following diagnoses: previous stroke or MI, angina pectoris or peripheral vascular disease.

Conclusions: Although RA was not an independent risk factor for ACS among all patients subjected to a cardiac diagnostic work-up in the ED, RA was an independent risk factor among patients presenting with chest pain as chief complaint, an association that was not readily explained by traditional cardiovascular risk factors. The combination of RA and chest pain should thus increase the suspicion of ACS.

Disclosure of Interest: None declared

DOI: 10.1136/annrheumdis-2018-eular.2968

\section{THU0138 OCCURRENCE OF IN-STENT RESTENOSIS AFTER CORONARY DRUG-ELUTING STENT IMPLANTATION IN PATIENTS WITH RHEUMATOID ARTHRITIS}

O.C. Kwon ${ }^{1}$, W.J. Seo ${ }^{2}$, J.S. Oh ${ }^{3}$, S. Hong ${ }^{1}$, C.-K. Lee ${ }^{1}$, B. Yoo ${ }^{1}$, Y.-G. Kim ${ }^{1}$. ${ }^{1}$ Division of Rheumatology, Department of Medicine, University of Ulsan, College of Medicine, Asan Medical Center, ${ }^{2}$ Division of Rheumatology, Department of Medicine, Seoul Veterans Hospital; ${ }^{3}$ Clinical Research Center, University of Ulsan College of Medicine, Asan Medical Center, Seoul, Korea, Republic of Ireland

Background: Rheumatoid arthritis (RA) is associated with increased risk of cardiovascular events. Thus, patients with RA have a greater chance of undergoing coronary drug-eluting stent (DES) implantation. However, it is not known whether the rate of in-stent restenosis (ISR) is also increased in RA patients.

Objectives: To investigate characteristics of in-stent restenosis (ISR) after drugeluting stent (DES) implantation in patients with rheumatoid arthritis (RA), and to evaluate the effect of disease modifying anti-rheumatic drugs (DMARDs) on ISR. Methods: Patients with RA who underwent DES implantation between January, 2005 and March, 2017 were included. Characteristics of the patients and the vessel lesions were reviewed retrospectively. To evaluate the effect of DMARDs on ISR, previously known ISR risk factors and ISR incidence were compared between the treated vessels of patients who did and did not receive specific DMARDs.

Results: In total, 30 RA patients (43 vessel lesions) were included. 4 treated vessel lesions developed ISR $(4 / 43,9.3 \%)$ in median 106.8 (81.1-109.0) months after DES implantation. Compared with the previous data in general population (occurrence of ISR: $3 \%-20 \%$, mean time of ISR occurrence: 13 months), the
Abstract THU0138 - Table 1. Comparison between treated vessels in the MTX group and treated vessels in the non-MTX group

\begin{tabular}{|c|c|c|c|}
\hline & $\begin{array}{l}\text { Treated vessels in the MTX } \\
\text { group }(n=31)\end{array}$ & $\begin{array}{l}\text { Treated vessel in the non- } \\
\text { MTX group }(n=12)\end{array}$ & $\begin{array}{c}\mathrm{p}- \\
\text { value }\end{array}$ \\
\hline \multicolumn{4}{|l|}{$\begin{array}{l}\text { General } \\
\text { characteristics }\end{array}$} \\
\hline Female, n (\%) & $16(51.6)$ & $5(41.7)$ & 0.558 \\
\hline HTN, n (\%) & 19 (61.3) & $5(41.7)$ & 0.245 \\
\hline Smoking, n (\%) & Current smoker, 4 (12.9) & Current smoker, 1 (8.3) & 0.615 \\
\hline Statin, n (\%) & $27(87.1)$ & $12(100.0)$ & 0.563 \\
\hline $\begin{array}{l}\text { Other csDMARDs, } \\
\mathrm{n}(\%)\end{array}$ & $26(83.9)$ & $12(100.0)$ & 0.300 \\
\hline DAS28-CRP & $1.54(1.36-1.90)$ & $1.51(1.25-1.93)$ & 0.547 \\
\hline \multicolumn{4}{|l|}{$\begin{array}{l}\text { Risk factors of } \\
\text { ISR }\end{array}$} \\
\hline Age (year) & $68.0(60.0-71.0)$ & $65.5(59.0-73.0)$ & 0.820 \\
\hline $\mathrm{DM}, \mathrm{n}(\%)$ & $13(41.9)$ & $5(41.7)$ & 0.987 \\
\hline $\begin{array}{l}\text { Vessel disease, } n \\
(\%)\end{array}$ & $\begin{array}{c}\text { 1-vessel disease, } 13(41.9) \\
\text { 2-vessel disease, } 13(41.9) \\
\text { 3-vessel disease, } 5 \text { (17.2) }\end{array}$ & $\begin{array}{l}\text { 1-vessel disease, } 2(16.7) \\
\text { 2-vessel disease, } 8 \text { (66.7) } \\
\text { 3-vessel disease, } 2 \text { (16.7) }\end{array}$ & 0.305 \\
\hline $\begin{array}{l}\text { Ostial lesion, } n \\
(\%)\end{array}$ & $3(9.7)$ & $2(16.7)$ & 0.608 \\
\hline $\begin{array}{l}\text { LAD involvement, } \\
\mathrm{n}(\%)\end{array}$ & $18(58.1)$ & $4(33.3)$ & 0.146 \\
\hline $\begin{array}{l}\text { Multiple lesions, } n \\
(\%)\end{array}$ & $10(32.3)$ & 7 (58.3) & 0.168 \\
\hline $\begin{array}{l}\text { Type of DES, } n \\
(\%)\end{array}$ & $\begin{array}{c}\text { Zotarolimus, } 9 \text { (29.0) } \\
\text { Everolimus, } 8 \text { (25.8) } \\
\text { Sirolimus, } 12(38.7) \\
\text { Paclitaxel+Cilostazol, } 1 \text { (3.2) } \\
\text { Biolimus, } 1 \text { (3.2) }\end{array}$ & $\begin{array}{c}\text { Zotarolimus, } 1 \text { (8.3) } \\
\text { Everolimus, } 6(50.0) \\
\text { Sirolimus, } 3(25.0) \\
\text { Paclitaxel+Cilostazol, } 2 \\
\text { (16.7) } \\
\text { Biolimus, } 0(0.0)\end{array}$ & 0.161 \\
\hline Diameter (mm) & $3.00(3.00-3.50)$ & $3.00(2.81-3.00)$ & 0.243 \\
\hline Length (mm) & $29.0(24.0-48.0)$ & $21.0(15.0-30.3)$ & 0.018 \\
\hline ISR, n (\%) & $0(0.0)$ & $4(33.3)$ & 0.004 \\
\hline
\end{tabular}

incidence was similar, but the time to ISR occurrence was much longer. In the comparison of patients receiving MTX ( $n=31$ vessel lesions) and those not receiving MTX ( $n=12$ vessel lesions), the ISR incidence was significantly different [0/31 $(0.0 \%)$ vs. $4 / 12(33.3 \%), p=0.004]$.

Conclusions: ISR after DES implantation in RA patients occurs in a similar rate, but after a much longer period of time than in the general population. Administration of MTX in patients with RA might have potential benefit to prevent ISR after DES implantation

Acknowledgements: None.

Disclosure of Interest: None declared

DOI: 10.1136/annrheumdis-2018-eular.3394

\section{THU0139 INCREASED HOMOCYSTEINE LEVEL FOR 7 YEARS IN PATIENTS WITH RHEUMATOID ARTHRITIS: TOMORROW STUDY}

K. Inui ${ }^{1}$, T. Koike ${ }^{2,3}$, Y. Sugioka ${ }^{3}$, T. Okano ${ }^{1}$, K. Mamoto $^{1}$, Y. Yamada ${ }^{1}$, K. Mandai $^{4}$ M. Tada ${ }^{5}$, H. Nakamura ${ }^{1} .{ }^{1}$ Department of Orthopaedic Surgery, Osaka City University Graduate School of Medicine, Osaka; ${ }^{2}$ Search Institute for Bone and Arthritis Disease (SINBAD), Shirahama Hamayu Hospital, Shirahama; ${ }^{3}$ Center for Senile Degenerative Disorders (CSDD), Osaka City University Graduate School of Medicine; ${ }^{4}$ Department of Orthopaedic Surgery, Osaka Social Medical Center Hospital; ${ }^{5}$ Department of Orthopaedic Surgery, Osaka City General Hospital, Osaka, Japan

Background: Osteoporosis is a disease in which not only bone density but also bone quality is low. Patients with rheumatoid arthritis (RA) are at higher proven risk of osteoporosis. Increased homocysteine (Hcy), one of the main markers of bone quality, is caused by insufficiency of folate or vitamin B. Elevation of Hcy inhibits physiological crosslink of collagen, which yields worse bone quality.

Objectives: In this study, we evaluated Hcy level as a bone quality marker in patients with RA for a period of 7 years and compared Hcy in RA patients with that in healthy volunteers (Vo).

Methods: We used the data for 7 years from a prospective cohort study (TOMORROW Study: UMIN000003876), which started in 2010 and compares data from RA patients with age- and sex-matched volunteer controls (Vo) recruited through mass media. Laboratory data were collected for all participants, including bone metabolic markers (urinary pentosidine, Hcy, collagen type 1 crosslinked N-telopeptide (NTX), and osteocalcin) and anthropometric parameters. Bone mineral density (BMD) of the lower leg was determined using wholebody dual-energy X-ray absorptiometry (DXA). Their parameters were compared with those of healthy controls, and multiple regression analysis was carried out 